\title{
PERAN PEKERJA SOSIAL DALAM PROGRAM REHABILITASI WANITA RAWAN SOSIAL EKONOMI DI BALAI PERLINDUNGAN DAN REHABILITASI SOSIAL WANITA YOGYAKARTA
}

\author{
THE ROLES OF SOCIAL WORKERS IN THE SOCIAL REHABALITATION PROGRAM AT \\ BALAI PERLINDUNGAN DAN REHABILITASI SOSIAL WANITA YOGYAKARTA
}

Oleh: Donny Dinardo, Pendidikan Luar Sekolah, UNY

\begin{abstract}
Abstrak
Penelitian ini mendeskripsikan : (1) Pelaksanaan program rehabilitasi sosial bimbingan, fisik, mental, dan sosial, (2) Peran pekerja sosial dalam program rehabilitasi sosial bimbingan fisik, mental, dan sosial, (3) Faktor pendukung dan penghambat pelayanan rehabilitasi sosial di Balai Perlindungan dan Rehabilitasi Sosial Wanita Yogyakarta. Penelitian ini merupakan penelitian deskriptif dengan pendekatan kualitatif. Lokasi penelitian di Balai Perlindungan dan Rehabilitasi Sosial Wanita Yogyakarta. Subyek penelitian ini adalah lima pekerja sosial. Pengumpulan data dilakukan dengan teknik observasi, wawancara, dan dokumentasi. Teknik analisis data menggunakan display data, reduksi data, dan kesimpulan dengan menguji keabsahan data menggunakan teknik trianggulasi sumber dan teknik. Hasil penelitian: (1) Program rehabilitasi sosial menggunakan sistem top down approach. Pelaksanaan program tersebut sesuai dengan jadwal kegiatan yang telah direncanakan oleh seksi PRS. Evaluasi akhir pelayanan rehabilitasi sosial dengan mengikutkan klien Praktik Belajar Kerja (2) Pekerja sosial memiliki peran sebagai motivator, pendamping, mediator, dan perantara. (3) Faktor pendukung pelayanan program rehabilitasi sosial, yaitu keikhlasan pekerja sosial dalam memberikan pelayanan, dan sarana prasarana yang memadai.
\end{abstract}

Kata Kunci : Peran Pekerja Sosial, Rehabilitasi Sosial, Wanita Rawan Sosial Ekonomi

\begin{abstract}
This study aims to describe: (1) Implementation of social guidance, physical, mental and social rehabilitation program, (2) The role of social workers in social rehabilitation program of physical, mental and social guidance, (3) Supporting factors and inhibiting social rehabilitation services at Balai Protection and Rehabilitation of Women in Yogyakarta. This research is a descriptive research with qualitative approach. Research location at Women's Center for Rehabilitation and Rehabilitation of Yogyakarta. The subjects of this study were five social workers. Data collection was done by observation, interview, and documentation. Data analysis techniques use display data, data reduction, and conclusions by testing the validity of data using triangulation techniques sources and techniques. Result of research: (1) Social rehabilitation program using top down approach system. Implementation of the program in accordance with the schedule of activities that have been planned by section PRS. The final evaluation of social rehabilitation services by involving clients Work Practice Practices (2) Social workers have a role as motivator, companion, mediator, and intermediary. (3) Supporting factors of social rehabilitation program services, namely the sincerity of social workers in providing services, and adequate of infrastructure.
\end{abstract}

Keywords: Role of Social Workers, Social Rehabilitation Woman with Socio-Economic Problem 


\section{Diklus: Jurnal Pendidikan Luar Sekolah, 1(2), September 2017 - 219 \\ Donny Dinardo}

menjadi kepala keluarga sebagai pencari nafkah untuk istri dan anak-anaknya. Namun tidak selamanya hubungan keluarga selalu harmonis. Ketika terjadi pertengkaran antara kedua orangtua dan pada akhirnya keutuhan keluarga tersebut tidak dapat diselematkan lagi sehingga berakhir pada perceraian, maka pihak wanita lah yang kemudian menjadi korbanya. Wanita tidak lagi mendapatkan nafkah dari suami, sehingga mereka mencari nafkah sendiri untuk mencukupi kebutuhanya sehari-hari. Bahkan akibat dari perceraian tersebut ada juga wanita yang menjadi ibu sekaligus bapak bagi anak-anaknya dengan kata lain membersarkan anaknya seorang diri atau disebut dengan wanita single parent.

Data Susenas Indonesia tahun 2007 menunjukan bahwa jumlah rumahtangga yang dikepalai kaum wanita mencapai $13,60 \%$ atau sekitar 6 juta rumahtangga, yang mencakup lebih dari 30 juta penduduk. Apabila dibandingkan dengan data tahun 2001, yakni kurang dari 13\%, data ini menunjukan kecenderungan peningkatan rata-rata $0,1 \%$ per tahun. Saat ini jumlah wanita kepala keluarga di negara Indonesia telah meningkat menjadi 7 juta. Sebagian wanita kepala keluarga ini masih didera sejumlah permasalahan, seperti kesulitan ekonomi, buta aksara, buta akses informasi, dan rentan terhadap tindak kekerasan.

Menurut data BPS Yogyakarta tahun 2015 jumlah penduduk di Yogyakarta berjumlah 3.691.196 orang, 1.866.467 merupakan wanita, dan 476.628 orang merupakan Penyandang Masalah Kesejahteraan Sosial (PMKS). Dari total jumlah PMKS tersebut 12.840 diantaranya merupakan wanita rawan sosial ekonomi (WRSE). Melihat data dari BPS Tersebut dapat disimpulkan bahwa lebih dari $25 \%$ penduduk Yogyakarta memiliki permasalahan kesejahteraan sosial ekonomi yang mana di dalamnya terdapat wanita rawan sosial ekonomi.

Selain faktor kemiskinan yang menjadi penyebab seorang wanita menjadi golongan wanita rawan sosial sosial ekonomi adalah faktor pendidikan dan faktor mental mereka. Dengan pendidikan yang relatif rendah menjadikan mereka kehilangan akal sehatnya dalam mencari cara untuk memenuhi kebutuhan hidupnya. Hal tersebut menyebabkan mereka terjerumus dalam penyimpangan sosial. Mencari nafkah dengan jalan singkat menjadi wanita tuna susila mereka lakukan bahkan tidak sedikit dari mereka mengalami korban tindak kekerasan pelecehan seksual, menjadi pengemis, pemulung, dan gelandangan.

Apabila mereka yang melakukan atau menjadi korban penyimpangan sosial dibiarkan maka dikhawatirkan generasi penerus yang berasal dari keluarga Penyandang Masalah Kesejahteraan Sosial tersebut akan memiliki kehidupan yang sama dengan dengan orangtua mereka. Maka dibutuhkanlah rehabilitasi sosial agar mereka dapat kembali menjalankan fungsi sosialnya. Rehabilitasi Sosial adalah proses refungsionalisasi dan pengembangan untuk memungkinkan seseorang mampu melaksanakan fungsi sosialnya secara wajar dalam kehidupan masyarakat.

Dari berbagai kasus penyimpangan sosial yang terjadi pada wanita rawan sosial ekonomi di 
Yogyakarta, terdapat lembaga sosial miliki pemerintah yang menanganani rehabilitasi sosial kepada wanita rawan sosial ekonomi yaitu Balai Perlindungan dan Rehabilitasi Sosial Wanita atau yang lebih dikenal dengan sebutan BPRSW Yogyakarta. Lembaga sosial ini berada di Godean, Yogyakarta. Sasaran dari BPRSW Yogyakarta adalah wanita usia 17-40 tahun dengan kondisi pribadi dan lingkungan mengalami disharmonisasi sosial, penyimpangan norma sehingga rawan terhadap gangguan sosial psikologis.

Pekerja sosial mempunyai kedudukan peranan yang sangat penting dan strategis dalam rangka meningkatkan kesejahteraan penyandang masalah sosial. Dapat dikatakan penting dan strategis karena pekerja sosial berhadapan langsung dengan warga binaan, sehingga permasalahan yang dihadapi oleh warga binaan dapat dengan mudah diketahui. Selain itu pekerja sosial diharapkan mampu menciptakan hubungan yang harmonis kepada warga binaan agar dalam proses pelayanan sosial berjalan sebagai mana mestinya. Sehingga pekerja sosial diharapkan mampu memberikan perananya dalam memberikan pelayanan rehabilitasi sosial sesuai dengan kebutuhan warga binaan.

Melihat beberapa kasus permasalahan sosial yang ada dimasyarakat tersebut, menjadi sebuah daya tarik tersendiri untuk meneliti tentang Peran Pekerja Sosial Dalam Program Rehabilitasi Wanita Rawan Sosial Ekonomi di BPRSW Yogyakarta.

\section{METODE PENELITIAN}

Pendekatan Penelitian
Penelitian ini ingin mendeskripsikan bagaimana peran pekerja sosial dalam program rehabilitasi wanita rawan sosial di BPRSW Yogyakarta. Penelitian ini bersifat deskriptif dengan pendekatan kualitatif. Pendekatan kualitatif memiliki prosedur penelitian yang menghasilkan data deskriptif yang berupa lisan atau kalimat tertulis bukan angka (Bogdan dan Taylor dalam Moleong, 2011: 4). Sedangkan penelitian kualitatif menurut Moleong (2011:6) adalah penelitian yang bermaksud untuk memahami fenomena tentang apa yang di alami oleh subjek penelitian secara holistik, dan dengan cara deskripsi dalam bentuk kata-kata dan bahasa pada suatu konteks khusus yang alamiah dan dengan memanfaatkan berbagai metode ilmiah.

Dimaksudkan untuk mendeskripsikan, menjelaskan, dan menggambarkan tentang peran pekerja sosial di BPRSW Yogyakarta dalam Program Rehabilatasi Wanita Rawan Sosial Ekonomi.

\section{Waktu dan Tempat Penelitian}

Penelitian ini dilaksanakan di Balai Perlindungan dan Rehabilitasi Sosial Wanita, yang beralamatkan di Cokrobedog, Sidoarum, Godean, Sleman, Yogyakarta.

Pertimbangan peneliti memilih tempat di Balai Perlindungan dan Rehabilitasi Sosial Wanita Yogyakarta dikarenakan :

1. BPRSW Yogyakarta merupakan salah satu lembaga kesejahteraan sosial yang di dalamnya terdapat pekerja sosial yang berperan aktif memberikan pelayanan rehabilitasi sosial kepada penyandang 


\section{Diklus: Jurnal Pendidikan Luar Sekolah, 1(2), September 2017 - 221 \\ Donny Dinardo}

masalah kesejahteraan sosial yang mana wanita rawan sosial ekonomi menjadi salah satu dari bagian PMKS tersebut.

2. BPRSW Yogyakarta merupakan salah satu lembaga kesejahteraan pemerintah yang memiliki program rehabilitasi sosial untuk wanita rawan sosial ekonomi menjadi salah satu dari bagian PMKS tersebut.

\section{Subyek Penelitian}

Dalam menentukan subjek penelitian didasarkan pada tujuan penelitian. Subyek penelitian dalam penelitian ini adalah pekerja sosial, kepala balai, pengelola program rehabilitasi sosial dan warga binaan nya yaitu wanita rawan sosial ekonomi yang mengikuti program rehabilitasi sosial di BPRSW.

Subyek penelitian dimaksudkan untuk mendapatkan informasi tentang pelaksanaan program rehabilitasi, peran pekerja sosial, faktor pendukung dan penghambat selama mengikuti program rehabilitasi sosial.

Sumber data data dalam penelitian ini terdapat dua jenis informan, yaitu informan kunci (key informan) dan informan pendukung. Pekerja sosial dan Kepala Sie PRS menjadi key informan dalam penelitian ini, sedangkan informan pendukungnya adalah Kepala Balai, warga binaan / klien, dan pengelola program rehabilitasi di BPRSW Yogyakarta.

\section{Teknik Pengumpulan Data}

Metode pengumpulan data adalah metode yang digunakan untuk mengumpulkan data untuk melihat peran pekerja sosial BPRSW Yogyakarta dalam program rehabilitasi wanita rawan sosial ekonomi. Pada Untuk memperoleh jenis data yang dibutuhkan penelitian, maka metode pengumpulan data yang digunakan dalam penelitian ini adalah observasi, wawancara dan dokumentasi. Observasi merupakan teknik pengumpulan data yang tidak menggunakan perkataan atau tidak disertai dengan komunikasi lisan (Djuju Sudjana, 2008:199). Wawancara adalah percakapan dengan maksud tertentu. Percakapan itu dilakukan oleh dua pihak, yaitu pewawancara (interviewer) yang mengajukan pertanyaan dan terwawancara (interviewee) yang memberikan jawaban (Moleong,2010: 186). Menurut Sugiyono (2013:240) dokumen merupakan catatan peristiwa yang sudah berlalu.

\section{Teknik Analisis Data}

Menurut Lofland dalam Moleong (2001: 112), menjelaskan bahwa sumber data utama dalam penelitian kualitatif ialah dalam bentuk kata-kata atau ucapan dari perilaku orang-orang yang diamati dalam penelitian ini. Sedangkan data tambahan adalah dalam bentuk non manusia. Kemudian data yang telah dikumpulkan akan dianalisis dengan metode deskriptif kualitatif. Proses analisis data cenderung menggunakan model analisis data dari Milles dan Hubberman dalam Sugiyono (2011 : 247 - 252) yaitu data reduction, data display, dan data conclusion drawing verification.

\section{HASIL PENELITIAN DAN PEMBAHASAN}

1. Pelaksanaan Program Rehabilitasi Sosial 


\section{Diklus: Jurnal Pendidikan Luar Sekolah, 1(2), September 2017 - 222 Donny Dinardo}

Pelaksanaan program rehabiliasi sosial di BPRSW Yogyakarta tidak lepas dari proses perencanaan, pelaksaaan, dan evaluasi program yang tersusun secara sistematis. Di BPRzSW Yogyakarta untuk perencaanaan program rehabilitasi sosial wanita rawan sosial ekonomi dikoordinasi oleh Seksi Perlindungan dan Rehabilitasi Sosial (PRS) sedangkan pekerja sosial berperan dalam pelaksaaan programnya.

Sistem perencanaan program Di BPRSW Yogyakarta menggunakan sistem top down approach atau kebijakan yang berasal dari pusat ke lembaga. Dalam prencanaanya program yang ada di BPRSW Yogyakarta berasal dari Kementrian Sosial kemudian disesuaikan dengan kondisi di Yogyakarta oleh Dinas Sosial Yogyakarta dan selanjutnya disesuaikan kembali dengan kebutuhan yang ada di BPRSW Yogyakarta.

Suatu program akan berjalan apabila sudah direncanakan dengan baik, perencaan tersebut tidak terlepas dari anggaran untuk program itu sendiri. BPRSW Yogyakarta memliki anggaran untuk melaksanakan program rehabilitasi sosial. Dalam prencanaanya program yang ada di BPRSW Yogyakarta berasal dari Kementrian Sosial kemudian disesuaikan dengan kondisi di Yogyakarta oleh Dinas Sosial Yogyakarta dan selanjutnya disesuaikan kembali dengan kebutuhan yang ada di BPRSW Yogyakarta. Dari hasil wawancara juga dapat diketahui bahwa anggaran operasional program rehabilitasi sosial di BPRSW Yogyakarta sudah direncakan satu tahun sebelunya. Sumber dana dari anggaran tersebut berasal dari APBN dan APBD DIY.

Melihat dari hasil observasi, dokumentasi, dan wawancara yang peneliti lakukan di BPRSW Yogyakarta peneliti mendapatkan gambaran dari pelaksanaan rehabilitasi sosial bimbingan fisik, mental, dan sosial. Dalam bimbingan fisik, mental, sosial pekerja sosial memiliki peran penting terhadap klien. Untuk bimbingan fisik mental sosial lebih cenderung berupa bimbingan konseling, disitulah peran penting peksos memberikan layanan rehabilitasi sosial kepada klien. Selain peksos juga terdapat tutor/ instruktur dan psikolog.

Dalam pelaksanaan rehabilitasi sosial yang di berikan kepada wanita rawan sosial di BPRWS Yogyakarta memiliki jadwal khusus yang dibuat untuk mempermudah dalam memberikan pelayanan program. Pada jadwal tersebut antara program satu dengan program lain telah disesuaikan agar tidak terjadi tabrakan jam pelaksanaan selain itu agar pembagian jam nya untuk setiap minggu nya bisa merata. Melihat dari data tersebut dapat diperoleh informasi bahwa pada bimbingan fisik, mental, dan sosial terdapat beberapa kegiatan yang diberikan kepada klien yang diberikan secara terjadwal baik pelayanan yang diberikan oleh pekerja sosial maupun intruktur/ tutor dibidangnya masing-masing. Pelayanan tersebut diberikan menggunakan beberapa metode yang pada umumnya menggunakan metode klasikal di dalam kelas. Tujuan dari dibuat jadwal setiap kegiatan yang ada adalah untuk menghindari 


\section{Diklus: Jurnal Pendidikan Luar Sekolah, 1(2), September 2017 - 223 \\ Donny Dinardo}

kebosanan dalam penyampaian materi dan tabrakan setiap kegiatanya.

Untuk mengetahui hasil diperlukan evaluasi. Pelaksanaan evaluasi di BPRSW Yogyakarta terdapat dua macam evaluasi yaitu evaluasi kinerja pegawai dan evaluasi perkembangan klien. Dalam pelaksanaan evaluasi kinerja pegawai khususnya kepada pekerja sosial di BPRSW Yogyakarta dievaluasi dengan standar yang ada di Pemerintah Daerah melalui rapat dinas. Kemudian pekerja sosial memberikan laporan hasil evaluasinya kepada BPRSW Yogyakarta. Tujuan dari evaluasi tersebut adalah untuk meningkatkan kinerja pelayanan dari pekerja sosial di BPRSW Yogyakarta.

Melihat dari hasil wawancara dan studi dokumentasi dapat diambil informasi bahwa evaluasi program rehabilitasi sosial di BPRSW Yogyakarta terdapat dua jenis yaitu evaluasi pelaksanaan program untuk mengetahui perkembangan klien dalam menerima layanan rehabilitasi sosial dan juga evaluasi kinerja pegawai hal ini dikhususkan kepada peksos dalam memberikan pelayananan rehabilitasi sosial. Evaluasi akhir adalah PBK yang diberikan kepada klien untuk mengetahui sejauh mana kemampuan keterampilan yang mereka mmiliki selama mengikuti pelayanan rehabilitasi sosial di BPRSW Yogyakarta.

\section{Peran Pekerja Sosial dalam Program}

\section{Rehabilitasi Sosial Bimbingan Fisik,} Mental, dan Sosial di BPRSW Yogyakarta

Pekerja sosial memiliki peran sebagai motivator. Peran sebagai motivator adalah suatu peran untuk memberikan motivasi, semangat, dukungan dan dorongan agar penerima motivasi dapat melakukan perubahan menjadi lebih baik. Peran pekerja sosial sebagai motivator di BPRSW Yogyakarta dapat dilihat dari sikap pekerja sosial yang kebapakan dan ke ibuan dalam memberikan pelayanan. Mereka memiliki keterampilan untuk memberikan motivasi layaknya sebagai orangtua kandung klien sendiri. Peran ini sangat terlihat dalam bimbingan konseling yang diberikan kepada klien. Setiap kali klien mengikuti bimbingan konseling, mereka selalu diberikan motivasi dari pekerja sosial.

Peran pekerja sosial sebagai motivator menurut Jim Ife dalam Miftahul Huda (2009:296) adalah peran sebagai animasi sosial yang bertujuan untuk mengaktifkan semangat, memberikan kekuatan atau motivasi kemampuan sasaran yang dapat dipergunakan dalam memecahkan masalah yang sedang mereka hadapi dalam suatu bentuk kegiatan bersama. Peran ini terlihat dalam pelayanan rehabilitasi sosial di BPRSW Yogyakarta dimana pekerja sosial selalu memberikan motivasi kepada klien nya agar mereka memiliki semangat dan dorongan untuk berubah kearah yang lebih baik lagi. Selain itu dalam memberikan motivasi yang dilakukan saat bimbingan konseling juga memperlihatkan keterampilan pekerja sosial dalam berkomunikasi dari ke hati. Melihat dari data tersebut dapat disimpulkan bahwa peran sebagai motivator 


\section{Diklus: Jurnal Pendidikan Luar Sekolah, 1(2), September 2017 - 224 \\ Donny Dinardo}

pekerja sosial di BPRSW Yogyakarta sesuai dengan teori yang dikemukakan oleh Jim Ife tersebut.

Peran pendamping merupakan peran pendukung dari suatu program yang bertujuan untuk memfasilitasi penerima program dalam hal ini adalah klien agar mereka mampu memenuhi kebutuhanya. Tujuan dari pendampingan ini untuk memberikan fasilitas kepada klien atau dengan kata lain menjadi fasilitator. Ketika klien kurang paham dengan materi yang disampaikan oleh instruktur maka disitulah pekerja sosial mendekati klien untuk memberikan pemahaman kembali. Ketika ada masalah teknis sarana prasarana pekerja sosial membantu untuk memperbaikinya. Peran pendamping yang diberikan pekerja sosial kepada klien di BPRSW Yogyakarta adalah mendampingi klien ketika mereka mengikuti bimbingan fisik, mental, dan sosial.

Sebagai mediator pekerja sosial berperan untuk membantu permasalahan yang ada pada klien. Pekerja sosial melakukan mediasi antara klien dengan pihak-pihak yang memiliki masalah. Klien yang bermasalah dengan keluarganya atau dengan orang lain akan dibantu oleh pekerja sosial dengan menjadi mediator untuk menyelesaikan permasalahanya. Permasalahan yang kerap ditemui adalah konflik antara klien satu dengan yang lain baik itu dalam satu wisma ataupun klien yang berada di wisma lain Dalam peran ini pekerja sosial akan memberikan saran dan masukan kepada klien untuk menemukan solusi agar permasalahanya cepat terselesaikan.

Melihat informasi yang ada di BPRSW Yogyakarta, peran pekerja sosial sebagai mediator sesuai dengan teori yang diungkapkan oleh W. Sheafor dan Charles R. Horejsi dan National Association of Social Woekers (NASW) dalam Adi Fahrudin (2012:72) dan teori peran pekerja sosial menurut Jim Ife dalam Miftahul Huda $(2009 / ; 296)$ bahwa peran sebagai mediator adalah peran yang diberikan oleh pekerja sosial kepada klien yang bertujuan untuk membantuk menyelesaikan konflik yang sedang mereka hadapi. Dalam hal ini pekerja sosial bersifat netral tidak memihak dengan pihak manapun.

Dalam perananya sebagai perantara pekerja sosial dapat menyalurkan klien dengan sumber-sumber bantuan yang menunjang pelaksanaan program rehabilitasi sosial itu sendiri. Untuk di BPRSW Yogyakarta klien mendapatkan bantuan pelayanan dari instansi terkait seperti puskesmas, kepolisian, kantor urusan agama, dan pengusaha-pengusaha yang menunjang program rehabilitasi wanita rawan sosial ekonomi di BPRSW Yogyakarta. Peran pekerja sosial sebagai perantara terlihat ketika pekerja sosial membantu klien untuk menghubungkan dengan instansi kesehatan seperti rumah sakit ketika klien sakit. Pelayanan tersebut diberikan melalui jaminan 


\section{Diklus: Jurnal Pendidikan Luar Sekolah, 1(2), September 2017 - 225 \\ Donny Dinardo}

kesehatan yang diupayakan okeh pekerja sosial dari dinas sosial.

Pada BPRSW Yogyakarta klien mendapatkan fasilitas pendukung antara lain fasilitas pendukung kesehatan dari puskesmas, pelayanan hukum dari kepolisian, pelatihan keterampilan dari instruktur bidang pelatihan, dan fasilitas dari LPK atau lembaga terkait yang digunakan untuk magang klien. Dalam teknis pelaksanaanya pekerja sosial berperan sebagai perantara antara klien dengan sumber layanan tersebut. Pekerja sosial menghubungkan klien dengan pihak-pihak yang menyediakan pelayanan tersebut.

\section{Faktor Pendukung dan Penghambat} Program Rehabilitasi Sosial Wanita Rawan Sosial Ekonomi di BPRSW Yogyakarta

Faktor Pendukung dalam program rehabilitasi sosial ini peran pekerja sosial dalam program rehabilitasi sosial wanita rawan sosial ekonomi di BPRSW Yogyakarta terlihat dalam bimbingan konseling yang diberikan kepada klienya. Ketika pekerja sosial memberikan pelayanan kepada klien tidak sedikit klien yang susah untuk diajak bekerjasama, klien yang masih berusia remaja antara 18-24 tahun memang sangatlah sulit bagi pekerja sosial untuk melakukan pendekatan agar mereka bisa menerima kehadiran pekerja sosial dalam kehidupanya. Namun pekerja sosial yang ada di BPRSW Yogyakarta dapat merubah keadaan itu dengan keikhlasan sepenuh hati dalam memberikan pelayanan kepada klien nya.

Selain itu, faktor yang mendukung adalah sarana dan prasarana yang memadahi. Balai Perlindungan dan Rehabilitasi Sosial Wanita Yogyakarta merupakan lembaga sosial di bawah naungan Dinas Sosial Yogyakarta yang memiliki sarana dan prasarana yang memadahi. Terlihat dari pengamatan yang peneliti lakukan dan dari hasil wawancara beberapa narasumber dari pekerja sosial, pengelola, klien, dan kepala BPRSW yang mengungkapkan bahwa fasilitas di BPRSW sudah bisa dikatakan memadahi. Hal ini dikarenakan BPRSW Yogyakarta mampu membuat anggaran tahunan yang sesuai dengan kebutuhan kliennya. Selain itu BPRSW Yogyakarta memiliki mitra kerja dengan instansi dan lembaga lainya. Kerjasama itu dapat dilihat pada fasilitas penunjang pelaksanaan progra rehabilitasi sosial yang ada di BPRSW Yogyakarta.

Program rehabilitasi sosial wanita rawan sosial di BPRSW Yogyakarta terdiri dari dua jenis yaitu bimbingan mental sosial dan keterampilan. Dalam pelayanan rehabilitasi pekerja sosial berperan dalam bimbingan mental sosial sedangkan instruktur berperan dalam program bimbingan keterampilan. Peran pekeerja sosial sebagai pendamping ini mememiliki peran penting, dikarenakan apabila klien kurang memahami apa yang disampaikan oleh instruktur maka disitulah peran pekerja sosial untuk memberikan pemahaman kembali.

Selain adanya faktor pendukung, dalam pelaksanaan program rehabilitasi adapun faktor 
Diklus: Jurnal Pendidikan Luar Sekolah, 1(2), September 2017 - 226

Donny Dinardo

yang menghambat. Faktor penghambat tersebut berupa kurangnya konsentrasi klien dalam mengikuti pelayanan rehabilitasi. Tidak semua klien dapat berkonsentrasi dengan apa yang sedang mereka ikuti, hal ini dikarenakan mereka memiliki masalah pribadi yang belum terselesaikan, belum sepenuh hati dalam mengikuti program rehabilitasi. Kurangnya konsentrasi klien ini dapat menghambat pemahaman materi yang telah diberikan oleh pekerja sosial.

Selain iu, Perubahan mood dari klien tidak hanya disbabkan oleh klien yang lainya namun motivasi dari diri mereka sendiri juga masih kurang stabil. Hal seperti ini menyebabkan klien akan tertinggal dalam menerima materi program yang diberikan karena ketika diberikan materi penting oleh pekerja sosial namun klien tersebut malah tidak mengikutinya karena pada hari itu sedang malas untuk mengikuti program. Klien yang kurang memahami manfaat dari program rehabilitasi juga menjadi salah satu faktor yang menghambat berjalannya program rehabilitasi sosial.

Faktor penghambat lainya berasal dari pekerja sosial itu sendiri. Kurangnya jumlah pekerja sosial di BPRSW Yogyakarta menjadi penghambat pelayanan. Ketika mereka sesang memiliki agenda/ kesibukan yang sama tetapi pada saat itu juga klien membutuhkan pelayanan pekerja sosial maka yang terjadi kebutuhan klien tidak dapat dijangkau oleh pekerja sosial. Kurangnya jumlah pekerja sosial juga menyebabkan mereka kurang dapat memahami karakter klien lebih dalam lagi.

\section{SIMPULAN DAN SARAN}

\section{Simpulan}

Pelaksanaan program rehabilitasi wanita rawan sosial ekonomi di BPRSW Yogyakarta terdapat 3 pengelolaan yaitu perencanaan, pelaksanaan dan evaluasi dimana masing-masing dari pengelolaan tersebut mempunyai komponenkomponen yang berbeda.

Peran pekerja sosial dalam program rehabilitasi wanita rawan sosial ekonomi di BPRSW Yogyakarta

Peran tersebut ialah memberikan motivasi dan semangat kepada klien agar tidak berputus asa dalam menjalani kehidupan sehari-hari dan selalu bersemangat dalam mengikuti pelayanan rehabilitasi sosial.

Pekerja sosial memiliki peran sebagai pendamping dapat dilihat dari peranananya bersama instruktur dalam mendampingi klien dalam bimbingan keterampilan. Pekerja sosial memiliki peran sebagai mediator dapat dilihat dari perananya memberikan mediasi antara klien yang sedang berkonflik baik sesama klien atau masalah yang ada di keluarga. Peran pekerja sosial sebagai perantara dapat dilihat dari adanya upaya pekerja sosial menyalurkan klien kepada sumber-sumber yang memberikan dukungan fasilitas pelayanan rehabilitasi sosial.

Dalam program rehabilitasi sosial terdapat faktor yang mendukung berjalannya program dan faktor yang menghambat. Faktor pendukung yang ada yaitu Dalam perananya pekerja sosial memberikan pelayanan rehabilitasi kepada klien memiliki fakor pendukung antara lain dari intern pekerja sosial itu sendiri yang memiliki keikhlasan dalam memberikan pelayanan, sarana prasanara yang memadahi dalam 


\section{Diklus: Jurnal Pendidikan Luar Sekolah, 1(2), September 2017 - 227 \\ Donny Dinardo}

menunjang pelaksanaan program rehabilitasi sosial, dan adanya kerja sama antara instruktur dengan pekerja sosial dalam memberikan pendampingan bimbingan keterampilan.

Kemudian, faktor yang menghambat antara lain berasal dari klien itu sendiri. Klien kurang bisa konsentrasi, mood yang labil saat mengikuti program rehabilitasi, kurangnya klien dalam memahami manfaat dari program rehabilitasi sosial, dan kurangnya jumlah pekerja sosial.

\section{Saran}

Berdasarkan termuan penelitian dlapangkan, ada beberapa saran yang ingin peneliti sampaikan antara lain :

1. Dalam bimbingan fisik mental sosial, pendekatan yang dilakukan pekerja sosial terhadap klien perlu lebih diperhatikan lagi agar klien lebih terbuka dengan pekerja sosial sehingga diharapkan klien dapat lebih mudah saat diberikan layanan rehabilitasi sosial.

2. Dalam mengikuti program rehabilitasi sosial, klien perlu meningkatkan keseriusanya agar fokus dalam mengikuti bimbingan yang diberikan oleh pekerja sosial.

3. Dalam pengelolalan sarana prasarana perlu dilakukan pengecekan keberfungsian alat secara berkala untuk memastikan alat tidak mengalami gangguan saat digunakan.
4. Seharusnya dalam melakukan need assesment tidak menggunakan sistem top down approach, tetapi menggunakan bottom up agar pelayanan yang diberikan sesuai dengan kebutuhan klien yang ada di BPRSW Yogyakarta.

\section{DAFTAR PUSTAKA}

Fahrudin, A. (2012). Pengantar Kesejahteraan Sosial. Bandung : Refika Aditama

Huda, M. (2009). Pekerjaan Sosial dan Kesejahteraan Sosial Sebuah Pengantar.Yogyakarta : Pustaka Pelajar

Moleong, L.J. (2005). Metodologi Penelitian Kualitatif. Bandung: PT Remaja Rosdakarya. (2011). Metodologi Penelitian Kualitatif. Bandung: Remaja Rosdakarya

Sudjana, D. 2008). Evaluasi Program Pendidikan Pendidikan Luar Sekolah untuk Pendidikan Nonformal dan Pengembangan Sumberdaya Manusia. Bandung: PT Remaja Rosdakarya.

Sugiyono. (2010). Memahami Penelitian Kualitatif. Bandung: CV. Alphabeta. 